\title{
Preparation of antioxidant rich low fat black grapes frozen yoghurt
}

\section{ARADHANA VERMA*1 And Ritu P. DUBEY ${ }^{2}$}

${ }^{1}$ Mahatma Gandhi Chitrakoot Gramoday Vishwavidyalaya, CHITRAKOOT (M.P.) INDIA

${ }^{2}$ Sam Higginbottom Institute of Agriculture, Technology and Sciences, ALLAHABAD (U.P.) INDIA

Email : thearadhana94aa @ gmail.com

\section{SUMMARY :}

Black grapes fruit frozen yoghurt is the fermentation with Lactobacillus bulgaricus (Subsequently L. bulgaricus) and Streptococcus salvarius $\mathrm{ssp}$. Culture bacteria apparently must be alive to provide benefits in the intestine tract. Black grapes fruit frozen yoghurt in the benefits of health effect promoted by consumption of grapes product are attributed to antioxidant rich and Polyphenol compound. As the largest group of polyphenols, flavonoid are the main candidates considered to have biological properties including antioxidant, anti-inflammatory, anti cancer, anti microbial, hypertension cardiovascular disease, obesity caused by free radical in the body which take up position in the body and compromises body's ability to resist foreign antigen further attacks health with the introduction of the antioxidant rich black grapes fruit frozen yoghurt.

KEY WORDS : Antioxidant, Black grapes, Yoghurt

How to cite this paper : Verma, Aradhana and Dubey, Ritu P. (2016). Preparation of antioxidant rich low fat black grapes frozen yoghurt. Internat. J. Proc. \& Post Harvest Technol., 7 (2) : 248-254. DOI: 10.15740/HAS/ IJPPHT/7.2/248-254. 